\title{
Engineered heat treated methanogenic granules: A promising biotechnological approach for extreme thermophilic biohydrogen production
}

\author{
Angela A. Abreu ${ }^{\text {a,b,*, Joana I. Alves }}{ }^{\text {b }}$, M. Alcina Pereira ${ }^{\mathrm{b}}$, Dimitar Karakashev ${ }^{\mathrm{a}}$, M. Madalena Alves ${ }^{\mathrm{b}}$, \\ Irini Angelidaki ${ }^{a}$ \\ a Department of Environmental Engineering, Technical University of Denmark, Bygningstorvet 115, DK-2800, Kgs Lyngby, Denmark \\ ${ }^{\mathrm{b}}$ Institute for Biotechnology and Bioengineering, Centre of Biological Engineering, University of Minho, 4710-057 Braga, Portugal
}

\section{A R T I C L E I N F O}

\section{Article history:}

Received 22 March 2010

Received in revised form 16 July 2010

Accepted 19 July 2010

Available online 23 July 2010

\section{Keywords:}

Extreme thermophilic biohydrogen

production

Dark fermentation

Engineered heat treated granules

\begin{abstract}
A B S T R A C T
In the present study, two granular systems were compared in terms of hydrogen production rate, stability and bacterial diversity under extreme thermophilic conditions $\left(70{ }^{\circ} \mathrm{C}\right)$. Two EGSB reactors were individually inoculated with heat treated methanogenic granules (HTG) and HTG amended with enrichment culture with high capacity of hydrogen production (engineered heat treated methanogenic granules EHTG), respectively. The reactor inoculated with EHTG $\left(R_{\mathrm{EHTG}}\right)$ attained a maximum production rate of $2.7 \mathrm{H} \mathrm{H}_{2} \mathrm{l}^{-1} \mathrm{day}^{-1}$ in steady state. In comparison, the $R_{\mathrm{HTG}}$ containing the HTG granules was very unstable, with low hydrogen productions and only two peaks of hydrogen $\left(0.8\right.$ and $\left.1.5 \mathrm{l} \mathrm{H}_{2} \mathrm{l}^{-1} \mathrm{day}^{-1}\right)$. The presence of active hydrogen producers in the $R_{\mathrm{EHTG}}$ system during the reactor start-up resulted in the development of an efficient $\mathrm{H}_{2}$-producing bacterial community. The results showed that "engineered inocula" where known hydrogen producers are co-inoculated with HTG is an efficient way to start up biohydrogen-producing reactors.
\end{abstract}

(ㄷ) 2010 Elsevier Ltd. All rights reserved.

\section{Introduction}

The search for new alternative fuels is a priority and hydrogen is a promising clean energy alternative to fossil fuels, since water is the only reaction product of oxidation. Chemoheterotrophic ("dark") fermentation process has received much attention recently due to the fact that hydrogen can be generated continuously at high rate from renewable organic materials (Das and Veziroglu, 2001). Dark fermentation generally results in a higher hydrogen production rate and higher bacterial growth than photofermentation (Levin et al., 2004). The possibility to produce $\mathrm{H}_{2}$ without the demand of light energy is another advantage of dark fermentation, resulting in lower capital costs for at least small-scale production facilities $\left(100-1000 \mathrm{l} \mathrm{H}_{2} \mathrm{~h}^{-1}\right.$ ) (Das and Veziroglu, 2001; Hawkes et al., 2007). Almost all studies of hydrogen production with mixed cultures have been performed under mesophilic $\left(26-40^{\circ} \mathrm{C}\right)$ or thermophilic $\left(45-60{ }^{\circ} \mathrm{C}\right)$ conditions. Recently, fermentation under extreme thermophilic conditions $\left(70^{\circ} \mathrm{C}\right)$, started to attract attention due to: much better pathogen destruction for residues coming from anaerobic fermentation process; lower risk of contamination with methano-

\footnotetext{
* Corresponding author. Address: Departamento de Engenharia Biológica, Universidade do Minho, Campus de Gualtar, 4710-057 Braga, Portugal. Tel.: +351 253 604 400; fax: +351253678986.

E-mail address: angela_abreu@deb.uminho.pt (A.A. Abreu).
}

genic organisms (van Groenestijn et al., 2002), higher rate of hydrolysis (Lu et al., 2008) and higher hydrogen yield (Kadar et al., 2004). Continuous processes for fermentative $\mathrm{H}_{2}$ production can be divided into two major categories; namely, suspended systems and immobilized systems (Oh et al., 2004). Suspended systems allow better mass transfer between microorganisms and substrates, but have difficulty in maintaining a sufficient amount of $\mathrm{H}_{2}$-producing bacterial population inside the bioreactor under low hydraulic retention time (Chen et al., 2001). Immobilized based systems have been used for hydrogen production since they are more capable of maintaining higher biomass concentration under high dilution rates without biomass washout (Zhang et al., 2008).

In general, immobilized-cell techniques include surface attachment (Oh et al., 2004), self-flocculation (Kim et al., 2005) and gel entrapment ( $\mathrm{Wu}$ et al., 2006) approaches. These techniques have been applied to produce $\mathrm{H}_{2}$ continuously in fixed-bed (or packed-bed) bioreactors (Lee et al., 2003), granular-sludge bed bioreactors (e.g., CIGSB) (Lee et al., 2004), trickling biofilter reactors (TBR) (Oh et al., 2004), up-flow anaerobic sludge blanket bioreactor (UASB) (Thong et al., 2008) and fluidized bed bioreactors (FBRs) (Lin and Cheng, 2006). In granularsludge systems, cell immobilization is achieved, under certain conditions, by self-aggregation of anaerobic microorganisms into granules, in the absence of a support material. A major drawback in granule based processes is the long start-up period, which 
generally requires several months for the formation of hydrogenproducing granules ( $\mathrm{Mu}$ and $\mathrm{Yu}, 2006$ ). Engineering microbial mixed communities present in already formed anaerobic granules towards improved hydrogen production, by means of environmental pressure, is thus an attractive alternative to circumvent the long start-up periods required for the development of hydrogen-producing granules. The bacterial community structures of hydrogen-producing systems have been extensively characterized. Diverse mesophiles and thermophiles affiliated with the classes Clostridia and Bacilli in the phylum Firmicutes have been reported ( $\mathrm{Wu}$ et al., 2006). However, there are few studies on community structure of hydrogen-producing anaerobic microflora at temperatures higher than $60^{\circ} \mathrm{C}$ (Thong et al., 2008; Yokoyama et al., 2007).

The aim of the present work was to compare two different start-up strategies for extreme thermophilic expanded granular sludge blanket (EGSB) reactor systems. The first EGSB reactor was inoculated with heat treated methanogenic granules (HTG), and the second with engineered heat treated methanogenic granules (EHTG), obtained by contact of HTG with an enriched hydrogen producing culture. The two strategies were compared in terms of hydrogen production rate, process stability and bacterial community structure. Synthetic medium used in this study contained glucose and arabinose, components of various plant biopolymers (hemicellulose and pectin) and lignocellulosic hydrolysates with a significant potential for biohydrogen production.

\section{Methods}

\subsection{Source of inocula}

Inoculum from $\mathrm{H}_{2}$ producing laboratory-scale continuously stirred tank reactor (CSTR) treating household solid wastes (HSW) at $70{ }^{\circ} \mathrm{C}$ (Liu et al., 2006) was used to obtain enriched culture with high hydrogen production potential by repeated batch cultivation. The CSTR was fed with HSW at a hydraulic retention time of 2 days and organic loading rate of $11 \mathrm{~g}$ volatile solids $\mathrm{l}^{-1} \mathrm{day}^{-1}$ at $70{ }^{\circ} \mathrm{C}$ for approximately 1 year, and was originally inoculated with the effluent from a mesophilic $\left(38^{\circ} \mathrm{C}\right)$ full-scale biogas plant treating a mixture of wastewater sludge and municipal solid wastes (Grindsted, Denmark).

Methanogenic granules were obtained from an up-flow anaerobic sludge blanket (UASB) reactor used for treating brewery wastewater (Lisbon, Portugal).

\subsection{Medium preparation and repeated batch cultivations}

Basal anaerobic (BA) medium was used for enrichment and routine cultivation in batch, as described previously (Angelidaki et al., 2004), except that no L-cysteine hydrochloride was added, and the concentration of $\mathrm{Na}_{2} \mathrm{~S} \cdot 9 \mathrm{H}_{2} \mathrm{O}$ was increased to $0.25 \mathrm{~g} \mathrm{l}^{-1}$. The medium was supplemented with sterile solutions of glucose, arabinose, yeast extract, and peptone to final concentrations of 2 , 2, 2 and $1 \mathrm{~g} \mathrm{l}^{-1}$, respectively. Forty millilitres medium was then dispensed in $100 \mathrm{ml}$ serum bottles. The medium was flushed with nitrogen for $15 \mathrm{~min}$ to obtain anaerobic conditions and the $\mathrm{pH}$ was adjusted to 7.0. After inoculation with $4 \mathrm{ml}$ inoculum from late exponential growth phase $\left(\mathrm{OD}_{660}=0.5\right)$, the serum bottles were incubated in dark at $70^{\circ} \mathrm{C}$. When the culture reached late exponential growth phase, it was used to make new inoculations in fresh BA medium with composition described above. Six repeated batch cultivation of the enriched mixed culture were performed.

\subsection{Set-up and operation of the $\mathrm{H}_{2}$-producing reactors}

\subsubsection{Pre-treatment of granules}

The methanogenic granules were boiled at $100{ }^{\circ} \mathrm{C}$ for $15 \mathrm{~min}$ (subsequently named, HTG) as described by Lay et al. (1999). The continuous experiments were carried out in EGSB reactors (Fig. 1) made of plexiglass with a height of $1.95 \mathrm{~m}$ and internal diameter of $21 \mathrm{~mm}$. Total liquid volume was 1.301 inclusive reaction-zone volume of 0.71 and the superficial velocity was set at $10.0 \mathrm{~m} \mathrm{~h}^{-1}$ by means of an internal recirculation. The reactors were operated with a stable temperature of $70 \pm 1^{\circ} \mathrm{C}$ by means of an external jacket for water circulation. One EGSB reactor, designated as $R_{\mathrm{HTG}}$, was inoculated with $400 \mathrm{ml}$ of HTG (47.6 $\mathrm{mg} \mathrm{VSS}^{-1}$ ). The second reactor, $R_{\mathrm{EHTG}}$, was inoculated with $400 \mathrm{ml}$ of HTG and $600 \mathrm{ml}\left(\mathrm{OD}_{660}=0.5\right)$ of the hydrogen producing enriched culture (obtained by repeated batch cultivation, as described above). After inoculation, $R_{\mathrm{EHTG}}$ was operated in a batch mode for 3 days only with recirculation in order to promote the contact between the culture and HTG surface. The recirculation flow rate was $20 \mathrm{ml} \mathrm{min}{ }^{-1}$. HTG amended with the enriched hydrogen culture were designated as EHTG (engineered heat treated methanogenic granules).

Thereafter, $R_{\mathrm{HTG}}$ and $R_{\mathrm{EHTG}}$ were operated continuously and fed with glucose and L-arabinose with ratio $1: 1(w / w)$ at final concentrations of $5 \mathrm{~g} \mathrm{COD}^{-1}$. The feedstock was supplemented with macronutrients, with the following composition: $\mathrm{MgSO}_{4} \cdot 7 \mathrm{H}_{2}$ $\mathrm{O}: 30.2 \mathrm{~g} \mathrm{l}^{-1} ; \mathrm{KH}_{2} \mathrm{PO}_{4}: 28.3 \mathrm{~g} \mathrm{l}^{-1} ; \mathrm{KCl}: 45 \mathrm{~g} \mathrm{l}^{-1}$. The macronutrients were added to the influent feed by addition of $0.6 \mathrm{ml} \mathrm{g}^{-1}$ COD fed. To give suitable alkalinity $2 \mathrm{~g} \mathrm{NaHCO}_{3}$ were added per litre of feed. The feedstock was stored at $4{ }^{\circ} \mathrm{C}$, to minimize acidification.

During the first 7 days of continuous mode, $R_{\mathrm{EHTG}}$ was operated with a hydraulic retention time (HRT) of $27 \mathrm{~h}$. $R_{\mathrm{EHTG}}$ was fed with $2 \mathrm{~g} \mathrm{COD}^{-1}$ for 4 days and afterwards the feed concentration was increased to $5 \mathrm{~g} \mathrm{COD} \mathrm{l}^{-1}$. HRTs of 14,8 and $6 \mathrm{~h}$ were applied in $R_{\mathrm{EHTG}}$ and these changes were performed when steady state in hydrogen production rate (more than 3HRT with hydrogen production rate variation less than $5 \%$ ) was achieved.

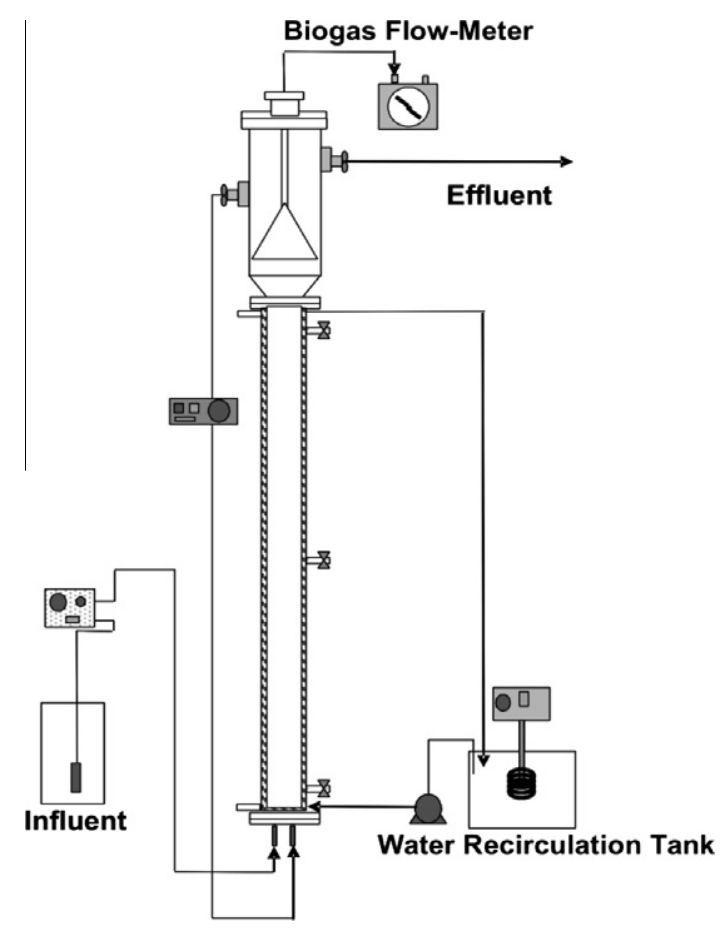

Fig. 1. EGSB reactor set-up. 


\subsection{Analytical methods}

The COD was determined according to Standard Methods (APHA, 1989). Biogas flow rate was measured by a Ritter Milligascounter (Dr. Ing. Ritter Apparatebau GmbH, Bochum, Germany). Hydrogen content of the gas phase was determined by gas chromatography (GC) using a Hayesep Q column (80/100 mesh) and thermal conductivity detector (Varian 3300 Gas Chromatograph) with nitrogen $\left(30 \mathrm{ml} \mathrm{min}^{-1}\right)$ as the carrier gas. The injector, detector, and column temperatures were 120,170 , and $35^{\circ} \mathrm{C}$, respectively. Methane content was determined by gas chromatography using a Porapack $Q$ (100-180 mesh) column, with helium as the carrier gas at $30 \mathrm{ml} \mathrm{min}^{-1}$ and thermal conductivity detector. Temperatures of the detector, injector and oven were 110,110 and $35^{\circ} \mathrm{C}$, respectively. Volatile fatty acids (VFA), ethanol, lactic acid, L-arabinose, and glucose were determined by high performance liquid chromatography using an HPLC (Jasco, Japan) with a Chrompack column $\left(6.5 \times 30 \mathrm{~mm}^{2}\right)$; sulphuric acid $(0.01 \mathrm{~N})$ at a flow rate of $0.7 \mathrm{ml} \mathrm{min}^{-1}$ was used as mobile phase. Column temperature was set at $60^{\circ} \mathrm{C}$. Detection of VFA and ethanol, lactic acid, L-arabinose, glucose was made sequentially with an UV detector at $210 \mathrm{~nm}$ and a RI detector, respectively.

\subsection{Scanning electron microscopy observations}

The surface structure of HTG and EHTG was observed by means of scanning electron microscopy (SEM) (Quanta 200F FEI, Oxford Instruments, Oxford). Sample preparation and fixation was preformed according to (Tay et al., 2001). The dried samples were sputter coated with Au-Pd (Sputter coater 208HR, Cressington) and finally observed by SEM.

\subsection{PCR-DGGE}

Representative granular sludge samples (mixture of granules, and suspended growing cells), collected from the reactors were stored at $-18{ }^{\circ} \mathrm{C}$ until use. Total genomic DNA was extracted from approximately $500 \mu \mathrm{L}$ of sample by using a FastDNA SPIN kit for soil (Qbiogene, Carlsbad, CA, USA). The extracted DNA was maintained at $-20^{\circ} \mathrm{C}$. Ten-fold serial dilutions from extracted DNA were made and tested in the PCR to find the best concentration of template DNA that gives a good specific product. The 16S rRNA genes were amplified by PCR using a Taq DNA polymerase kit (Life Technologies, Gaithersburg, MD, USA), with primers targeting conserved domains. Bacterial $16 \mathrm{~S}$ rRNA genes were selectively amplified for cloning using primers Bact27-f ( $5^{\prime}$-GTT TGA TCC TGG CTC AG-3') and Uni1492-r ( $5^{\prime}$-CGG CTA CCT TGT TAC GAC-3'). The thermocycling program used for amplification was as follows: predenaturation at $95{ }^{\circ} \mathrm{C}$ for $5 \mathrm{~min} ; 25$ cycles of denaturation at $95{ }^{\circ} \mathrm{C}$ for $30 \mathrm{~s}$, annealing at $52{ }^{\circ} \mathrm{C}$ for $40 \mathrm{~s}$, and elongation at $72{ }^{\circ} \mathrm{C}$ for $90 \mathrm{~s}$; and post-elongation at $72^{\circ} \mathrm{C}$ for $5 \mathrm{~min}$. The reactions were subsequently cooled to $4{ }^{\circ} \mathrm{C}$. For DGGE analysis, DNA fragments of 456 base pairs were amplified by PCR using the primer set of 954GC-f ( $5^{\prime}$-GCA CAA GCG GTG GAG CAT GTG G-3') plus GC-Clamp (5'- CGC CCG GGG CGC GCC CCG GGC GGG GCG GGG GCA CGG GGG G-3') and 1369-r (5'- GCC CGG GAA CGT ATT CAC CG-3'), targeting the V6-V8 regions of bacterial 16S rRNA (Yu and Morrison, 2004). The programme for amplification was as described above but with 35 cycles and an annealing temperature of $56^{\circ} \mathrm{C}$. The size of the obtained PCR products was checked by comparison with appropriate size and mass standard (MBI Fermentas, Vilnius, Lithuania), by electrophoresis on an $1 \%(\mathrm{w} / \mathrm{v})$ agarose gel and ethidium bromide staining. Gels ran at a constant voltage of $100 \mathrm{~V}$ in an agarose gel electrophoresis system (Mupid-EX, Belgium). Nucleic acids were detected using an UV transilluminator (Bio-Rad).
DGGE analysis of the amplicons was done by using the DCode system (Bio-Rad, Hercules, CA, USA). PCR products were electrophoresed in a $0.5 \times$ Trisacetate-EDTA buffer for $16 \mathrm{~h}$ at $85 \mathrm{~V}$ and $60{ }^{\circ} \mathrm{C}$ on polyacrylamide gel (8\%) containing a linear gradient ranging from $30 \%$ to $60 \%$ denaturant. Silver staining of DGGE gels was performed as previously described by (Sanguinetti et al., 1994). DGGE gels were scanned at $400 \mathrm{dpi}$ and the DGGE profiles compared using the Bionumerics 5.0 software package (Applied Maths, Belgium). Similarity indices ( $\mathrm{Si}$ ) of the compared profiles were calculated from the densitometric curves of the scanned DGGE profiles by using the Pearson product-moment correlation (Hane et al., 1993). Community shifts were described as changes in the DGGE profiles of the partial 16S rDNA amplicons.

Shannon-Wiener diversity indices $(H)$ were calculated on the basis of the intensities of the bands on the gel tracks, as judged by peak height in the densitometric curves, according to the equation: $H=-\Sigma\left(P_{i} \ln \left(P_{i}\right)\right)$ where, $H$ is the diversity index and $P_{i}$ is the importance probability of the bands in a lane $\left(P_{i}=n_{i} / N\right.$, where $n_{i}$ is the height of an individual peak and $N$ is the sum of all peak heights in the densitometric curves).

\subsection{Cloning and sequencing}

PCR products obtained with the primers pair Bact27f and 1492r, described above, were further purified with the Nucleo Spin Extract II kit (Clontech Laboratories), ligated into thepGEM-T vector using the pGEM Easy Vector Systems kit (Promega), and introduced into competent Escherichia coli ${ }^{\circledR}$ 10G \& 10GF' (Lucigen $^{\circledR}$ Corporation), according to the manufacturer's instructions. Positive transformants were selected (by blue/white screening) and grown in appropriate media supplemented with ampicillin. After cell lysis, plasmids were amplified using the primer set PG1f ( $5^{\prime}$-TGG CGG CCG CGG GAA TTC-3') and PG2r (5'-GGC CGC GAA TTC ACT AGT G-3') and the obtained PCR products were analyzed in agarose gel $(1 \%)$ in order to select clones with right insert fragments. Amplicons of the correct size were screened by amplified ribosomal DNA restriction analysis (ARDRA), using the restriction enzymes MspI, Cfol, and AluI (Promega). The restriction fragments were analyzed by electrophoresis in a $2 \%(\mathrm{w} / \mathrm{v})$ agarose gel and visualized with ethidium bromide. Plasmids of selected transformants, with different ARDRA patterns and corresponding to predominant bands in the DGGE community fingerprint, were purified (Nucleo Spin Extract II kit) and subjected to DNA sequence analysis. Sequencing reactions were performed at BIOPREMIER (Lisboa, Portugal) using pGEM-T vector-targeted sequencing primers SP6 (5'-GAT TTA GGT GAC ACT ATA G-3') and T7 (5'-TAA TAC GAC TCA CTA TAG GG-3'). Similarity searches for the 16S rRNA gene sequences with approximately $1400 \mathrm{bp}$ derived from the sludge clones were performed using the NCBI BLAST search program within the GenBank database.

\subsection{Nucleotide sequence accession numbers}

Sequences of the 16S rRNA gene clones were deposited in the GenBank database under accession numbers GU296463GU296478.

\section{Results and discussion}

\subsection{Reactors performance - EHTG versus HTG}

\subsubsection{Hydrogen production}

$R_{\text {EHTG }}$ showed a stable hydrogen production rate during the entire operational period and in each HRT, steady state was achieved (Fig. 2a). The maximum hydrogen production rate under steady 


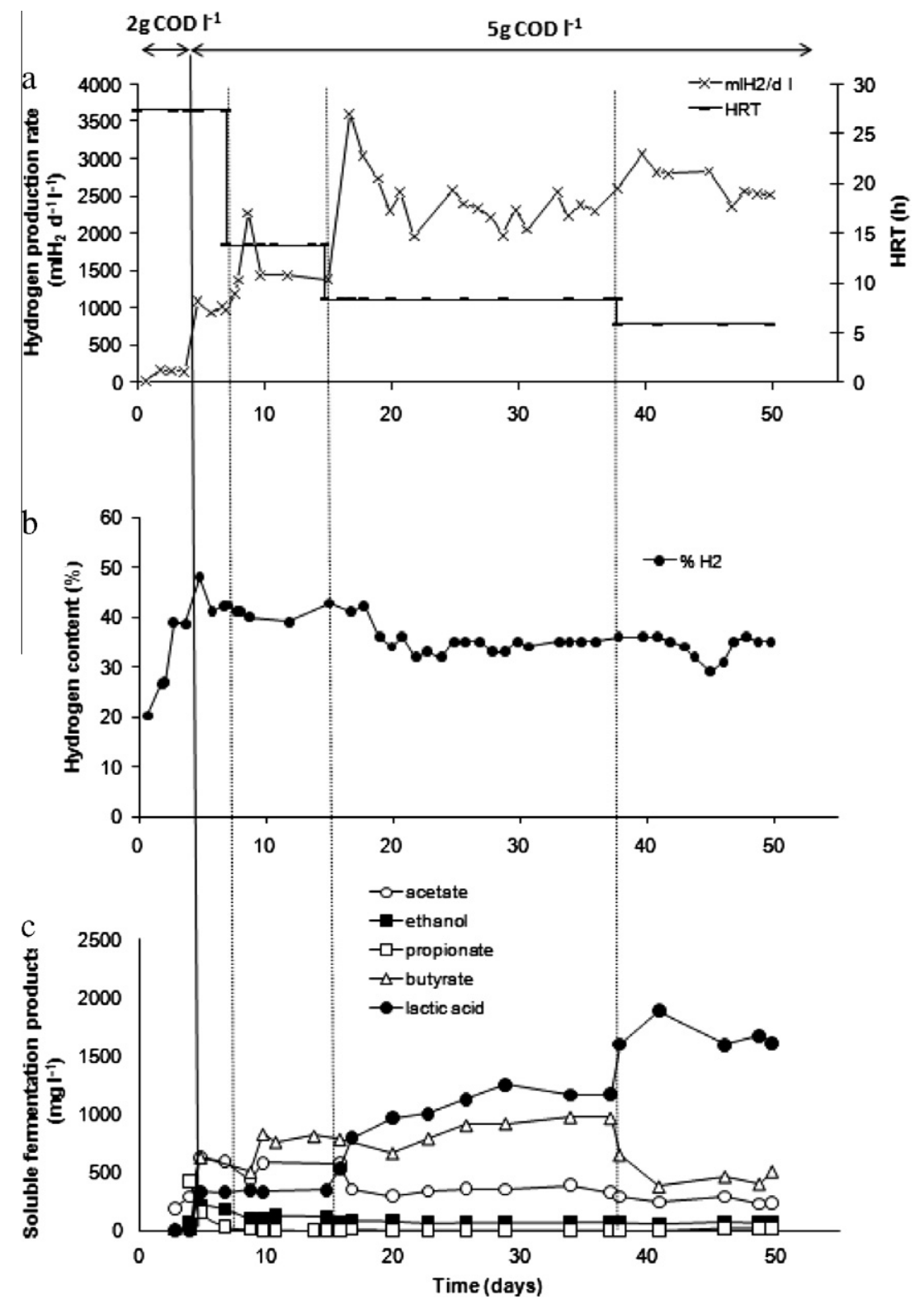

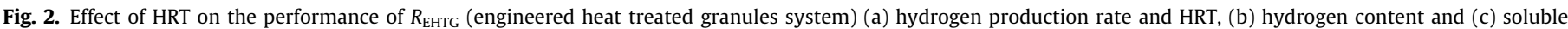
microbial products. Data represent average value from triplicate experiment, standard deviations were always within 5-10\%.

state $\left(2700 \mathrm{ml} \mathrm{H}_{2} \mathrm{l}^{-1}\right.$ day $\left.^{-1}\right)$ was attained with HRT of $6 \mathrm{~h}$, although no significant difference was observed between HRT 6 and $8 \mathrm{~h}$. Hydrogen content in the produced biogas was stable during the entire operation and varied between $30 \%$ and $40 \%$ (Fig. 2b). $R_{\text {EHTG }}$ achieved the highest hydrogen yield $(175 \mathrm{ml}$ $\mathrm{H}_{2} \mathrm{~g}^{-1}$ substrate) with HRT of $27 \mathrm{~h}$ and feed concentration of $5 \mathrm{gl}^{-1}$ (Table 1). No methane was detected in the gas phase. By contrast, in $R_{\mathrm{HTG}}$, almost no hydrogen production was observed during the entire operational period (Fig. 3a). Transient hydrogen production peaks were observed between days 13 and 18 (maximum rate of $800 \mathrm{ml} \mathrm{H}_{2} \mathrm{l}^{-1}$ day $^{-1}$ under HRT of $13 \mathrm{~h}$ ) and between days 30 and 36 (maximum rate of $1500 \mathrm{ml} \mathrm{H}_{2} \mathrm{l}^{-1}$ day $^{-1}$ under HRT of $8 \mathrm{~h}$ ). During the rest of the operational period, hydrogen production rate was less than $100 \mathrm{ml} \mathrm{H}_{2} \mathrm{l}^{-1}$ day $^{-1}$. In addition, hydrogen content in $R_{\mathrm{HTG}}$ was less than $18 \%$ during the entire operational period, except in the periods that corresponded to peaks of hydrogen production (44\% and 52\%) (Fig. 3b). Significant hydrogen production and process stability was obtained in engineered heat treated granules system. The performance of $R_{\mathrm{EHTG}}$ was comparable to other studies with extreme thermophilic hydrogen producers. Kotsopoulos and co-authors reported hydrogen production rates ranging from 636 to $1100 \mathrm{ml} \mathrm{H}_{2} \mathrm{l}^{-1}$ day $^{-1}$, depending on

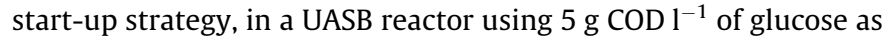
carbon source, and HRT ranging from 26 to $24 \mathrm{~h}$. The inoculum was compost by autoclaved granules that functioned as carriers for immobilization of a mixed culture (Kotsopoulos et al., 2006). In the present study $1000 \mathrm{ml} \mathrm{H}_{2} \mathrm{l}^{-1}$ day $^{-1}$ was achieved with a HRT of $27 \mathrm{~h}$ using the same feed concentration as these authors (Kotsopoulos et al., 2006) but more complex feed composition (mixture of glucose and arabinose (1/1)). van Groenestijn and co-authors (van Groenestijn et al., 2009) fed a sucrose solution to a continuous reactor at a load 3.75 times higher than that used in our study. The 4.8 times higher hydrogen production rate obtained by these authors, was likely due to the simpler feed composition used (sucrose versus mixture of arabinose and glucose) and the inoculation with a pure culture of Caldicellulosiruptor sacharolyticus. 
Table 1

Process performance of $R_{\text {ehtg }}$ system and $R_{\mathrm{htg}}$ system.

\begin{tabular}{|c|c|c|c|c|c|c|c|c|c|c|c|}
\hline \multicolumn{6}{|c|}{ Engineered heat treated granules system } & \multicolumn{6}{|c|}{ Heat treated granules system } \\
\hline $\begin{array}{l}\text { Feed } \\
\text { concentration } \\
\left(\mathrm{g} \mathrm{COD} \mathrm{l}^{-1}\right)\end{array}$ & $\begin{array}{l}\text { HRT } \\
(h)\end{array}$ & $\begin{array}{l}\text { Glucose } \\
\text { utilization }{ }^{a} \\
(\%)\end{array}$ & $\begin{array}{l}\text { Arabinose } \\
\text { utilization }^{a} \\
(\%)\end{array}$ & $\begin{array}{l}\text { Conversion rate } \\
\left(\mathrm{ml} \mathrm{H}_{2} \mathrm{~g}^{-1}\right. \\
\text { substrate } \\
\text { consumed })^{\mathrm{a}}\end{array}$ & $\begin{array}{l}\text { COD } \\
\text { balance } \\
(\%)\end{array}$ & $\begin{array}{l}\text { Feed } \\
\text { concentration } \\
\left(\mathrm{g} \mathrm{COD} \mathrm{l}^{-1}\right)\end{array}$ & $\begin{array}{l}\text { HRT } \\
(h)\end{array}$ & $\begin{array}{l}\text { Glucose } \\
\text { utilization } \\
(\%)\end{array}$ & $\begin{array}{l}\text { Arabinose } \\
\text { utilization }^{\mathrm{b}} \\
(\%)\end{array}$ & $\begin{array}{l}\text { Conversion rate } \\
\left(\mathrm{ml} \mathrm{H}_{2} \mathrm{~g}^{-1}\right. \\
\text { substrate } \\
\text { consumed })^{\mathrm{c}}\end{array}$ & $\begin{array}{l}\text { COD } \\
\text { Balance } \\
(\%)\end{array}$ \\
\hline $2(1$ arab +1 gluc $)$ & 27 & 100 & 100 & $68 \pm 3$ & 105 & & & & & & \\
\hline \multirow[t]{4}{*}{$5(2.5 \mathrm{arab}+2.5$ gluc $)$} & 27 & 100 & 72 & $175 \pm 7$ & $87 \pm 4$ & & & & & & \\
\hline & 14 & 100 & $79 \pm 3$ & $126 \pm 3$ & $90 \pm 7$ & $5(2.5$ arab +2.5 gluc $)$ & 13 & 100 & $31 \pm 8$ & 50 & $90 \pm 5$ \\
\hline & 8 & 100 & $74 \pm 5$ & $130 \pm 8$ & $109 \pm 0.3$ & & 8 & 100 & $45 \pm 9$ & 6 & $80 \pm 2$ \\
\hline & 6 & $94 \pm 5$ & $60 \pm 7$ & $95 \pm 1$ & $101 \pm 2$ & & & & & & \\
\hline
\end{tabular}

a Steady state average.

b Average of all values from each HRT.

c No steady state achieved, the values correspond to peaks of conversion rate.
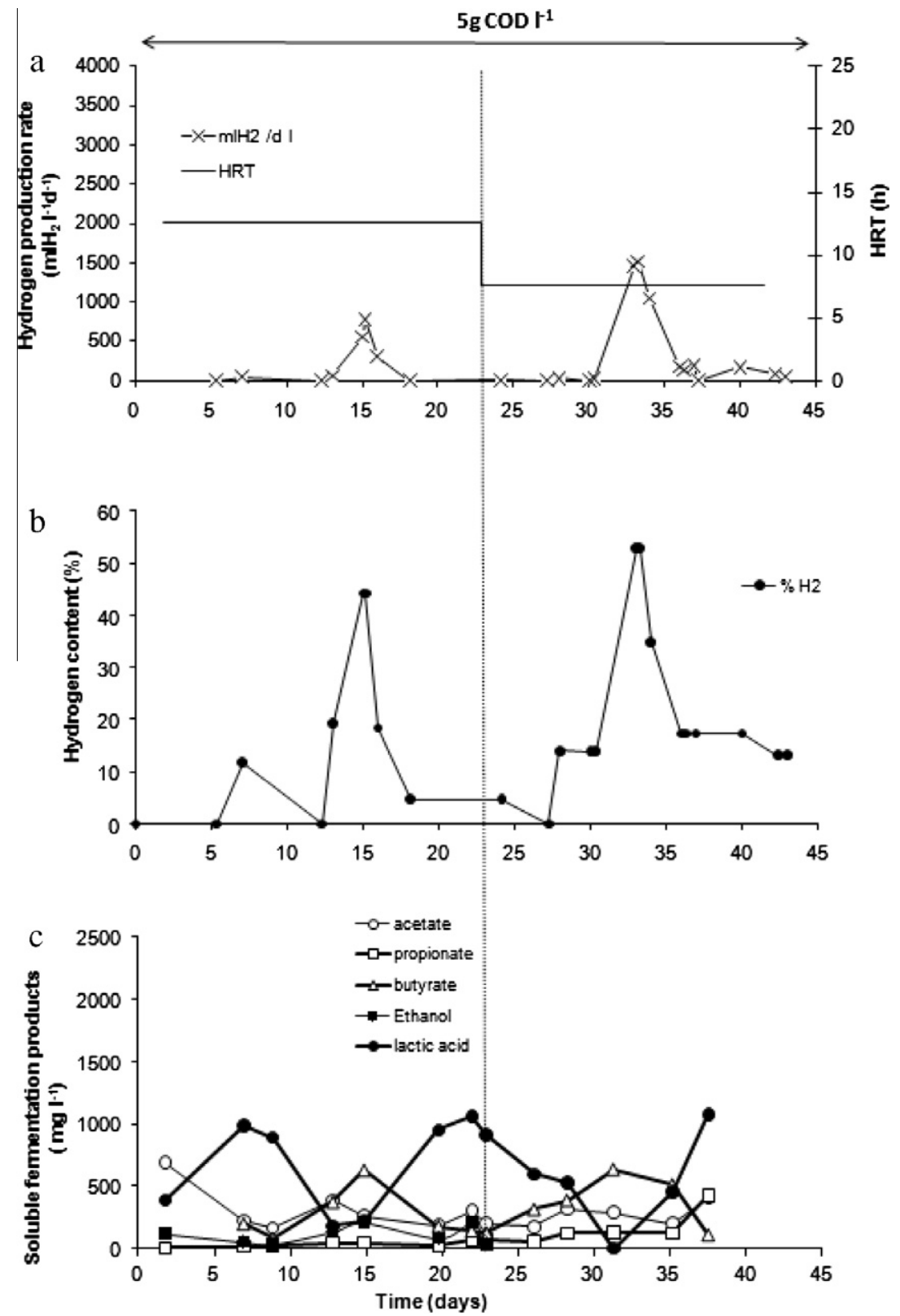

Fig. 3. Effect of HRT on the performance of $R_{\mathrm{HTG}}$ (self-formatted heat treated granules system) (a) hydrogen production rate and HRT, (b) hydrogen content and (c) soluble microbial products. Data represent average value from triplicate experiment, standard deviations were always within $5-10 \%$. 


\subsubsection{Sugar consumption}

Glucose was totally consumed in both reactors, except in $R_{\mathrm{EHTG}}$ with application of HRT of $6 \mathrm{~h}$ (Fig. 4a, b and Table 1). Uptake of arabinose in $R_{\mathrm{HTG}}$ was less than in $R_{\mathrm{EHTG}}$ independently of the HRT applied (Table 1 ). In $R_{\mathrm{EHTG}}$, the arabinose utilization was 2.5 times higher for the HRT of $14 \mathrm{~h}$ and 1.6 times higher for the HRT of $8 \mathrm{~h}$ compared to $R_{\mathrm{HTG}}$ (Table 1 ). All sugars were consumed in $R_{\mathrm{EHTG}}$ during the first days of operation, with the application of $2 \mathrm{~g} \mathrm{COD} \mathrm{l}^{-1}$ total feed concentration. However, an increase of residual arabinose was observed in $R_{\mathrm{EHTG}}$ immediately after each decrease of HRT and when the total feed concentration was increased to $5 \mathrm{~g} \mathrm{l}^{-1}$ (Fig. 4b). The residual arabinose gradually decreased and stabilized around $600 \mathrm{mg} \mathrm{l}^{-1}$ for each HRT applied.

The present study indicates that glucose was preferentially consumed than arabinose when the feed concentration was higher than $2 \mathrm{~g} \mathrm{COD} \mathrm{l}^{-1}$. The increase of residual arabinose in $R_{\mathrm{EHTG}}$ immediately after lowering the HRT, suggest that the system needs some adaptation time to a new arabinose loading condition. This adaptation time was not observed for glucose, which was totally consumed after each decrease of HRT. Differences in simple sugars uptake can be explained with the different metabolic pathway of arabinose (pentose) versus glucose (hexose) catabolism (Hames and Hooper, 2000). Arabinose fermentation requires various enzymes, and consequently its biochemical reactions are relatively complex (Hames and Hooper, 2000). The complexity of metabolic pathways and the involvement of various enzymes can be one of the reasons for the transitory periods and preferential consumption of glucose. It is also known that, the presence of a rapidly biodegradable carbon (glucose) can inhibit the synthesis of enzymes involved in the metabolism of other carbon-containing compounds. The phenomenon is known as "the glucose effect" (Strobel, 1993) of repression of the other sugars catabolism.

\subsubsection{Soluble fermentation products (SFP) profile}

$R_{\mathrm{HTG}}$ showed a very unstable SFP profile with lactic acid as the most dominant fermentation product, apart from the periods of hydrogen production peaks where butyrate was the major SFP (Fig. 3c). Acetate and butyrate were the main fermentation products in $R_{\text {EHTG }}$ during the application of HRT 27 and 14 h (Fig. 2c). Thus, the bacterial metabolism in $R_{\mathrm{EHTG}}$ during these periods was likely following butyrate-acetate type fermentation, responsible for high hydrogen yields in dark fermentation (Noike and Mizuno, 2000). However, other dominant SFP, i.e. lactate, became evident with the application of lower HRTs ( 8 and $6 \mathrm{~h}$ ). A butyrate-lactate fermentation type was probably occurring for the HRT of $8 \mathrm{~h}$. The application of HRT of $6 \mathrm{~h}$ further induced a dominance of lactate and a decline of butyrate as fermentation products in $R_{\mathrm{EHTG}}$. Propionate and ethanol were present in both reactors but the concentrations in most of the operation time were less than $250 \mathrm{mg} \mathrm{l}^{-1}$. COD mass balance showed that the recovery of COD was high (80-109\%), indicating that experimental measurements were accurate (Table 1 ). The shift on the metabolic pathway from butyrate/ acetate fermentation to lactate observed in $R_{\mathrm{EHTG}}$ was previously referred in other investigations on biohydrogen production (Liu et al., 2008). These authors indicated that lactic acid can be deemed as an indicator of organic overloading/inhibition for hydrogen
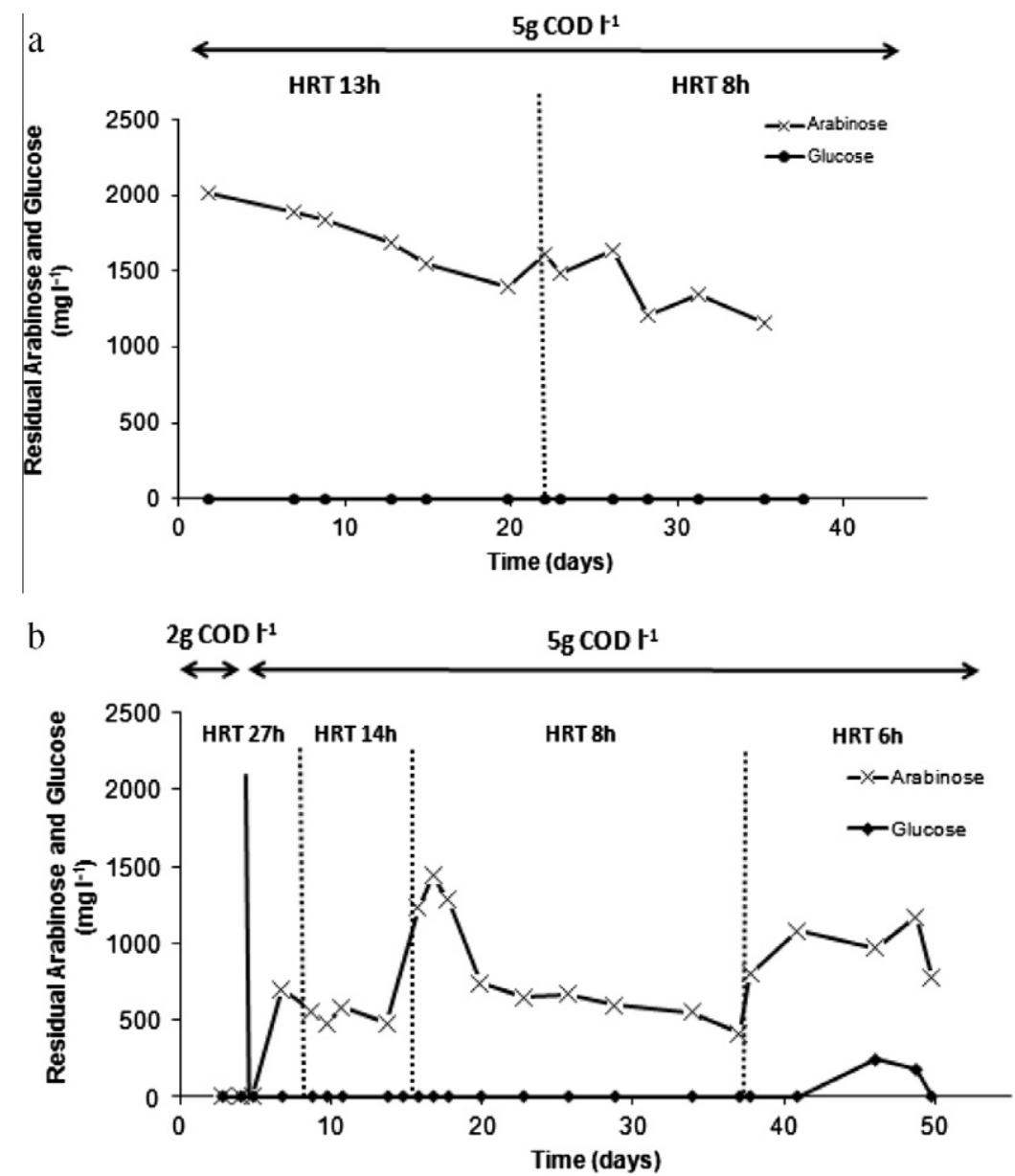

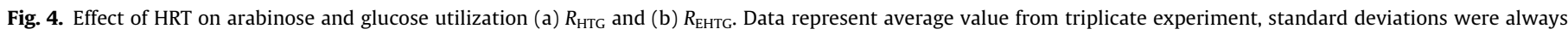
within $5-10 \%$. 
fermentation process. Another study (Noike et al., 2002) reported the negative effect of lactic acid on continuous hydrogen production by a mixed culture, suggesting that the inhibition was caused by bacteriocins secreted by lactic acid bacteria. In the present study the substrate conversion rate to hydrogen was maintained with the HRT $8 \mathrm{~h}$, as well as the arabinose and glucose utilization, suggesting that the system was not overloaded during this period. Only with the application of HRT 6 h the hydrogen yield decreased, suggesting that the system was probably overloaded. The increase of lactic acid could be also associated with the increase of hydrogen partial pressure already reported in other studies (Levin et al., 2004).

\subsection{Microbial community profiles}

Granules after heat treatment (HTG), used as $R_{\mathrm{HTG}}$ inoculum, and granules after the contact with the enriched culture (EHTG), used as $R_{\mathrm{EHTG}}$ inoculum, were analyzed in terms of bacterial community composition. The bacterial diversity established from the DGGE profiles, of each inoculum, was measured as Shannon diversity index $(H)$. $R_{\mathrm{HTG}}$ inoculum presented lower Shannon diversity index (0.59) than $R_{\mathrm{EHTG}}$ inoculum (1.18), evidencing the importance of the contact of HTG with the enriched culture (E) for the increase of inoculum diversity. The surface of HTG and of EHTG was also observed using SEM. The HTG exhibited an amorphous surface, while the presence of cocci- and bacillus-like cell type morphologies was observed in the granules surface of the EHTG (Supplementary Fig. S1). This highlights cellular integrity on the surface of EHTG, resulting most likely from the attachment of cells from the enriched culture. Comparison of the bacterial DGGE profiles obtained for EHTG and for the enriched culture (E) further supported the occurrence of attachment of specific microorganisms from the enriched culture in EHTG, as indicated by the presence of bands resolving at the same position in the gel (Fig 5). The specific bacterial community profiles in the granules of the two reactors had obviously been crucial for the different performance observed.

Along with the operation time, samples were taken from $R_{\mathrm{HTG}}$ and from $R_{\mathrm{EHTG}}$, and their bacterial community composition was analyzed. Table 2 summarizes the condition prevailing at the time of sampling. The similarity indices (SI) between the DGGE profiles of each sample were compared. A high shift in the community composition compared to the original granules was observed during the first period of operation in both $R_{\mathrm{HTG}}$ and $R_{\mathrm{EHTG}}$, with similarity indices of $25 \%$ and $3 \%$, respectively (Fig. 5).

Along operation time, the microbial community profile of $R_{\mathrm{EHTG}}$ went through a more pronounced change compared to bacterial community profiles of the $R_{\mathrm{HTG}}$, as indicated from the lower similarity indices $R_{\mathrm{EHTG}}$ system ( $R_{\mathrm{EHTG} 1} / R_{\mathrm{EHTG} 2} 36 \%, R_{\mathrm{EHTG} 2} / R_{\mathrm{EHTG} 3} 42 \%$ and $R_{\mathrm{EHTG} 3} / R_{\mathrm{EHTG}} 53 \%$ ) compared to corresponding profiles from HTG system ( $R_{\mathrm{HTG} 1} / R_{\mathrm{HTG} 2} 97 \%$ and $\left.R_{\mathrm{HTG} 2} / R_{\mathrm{HTG} 3} 98 \%\right)$.

Further characterization of the bacterial community revealed that the dominant ribotypes in the enriched culture were most closely affiliated to Thermoanaerobacter-like organisms (99-100\% identity) and Caldicoprobacter-like organisms (99\%) (Table 3). Besides this major genus, clone inserts with sequences similar to those of uncultured bacterium related to Clostridia class was also retrieved from the enriched culture. The clone corresponding to band 10 showed $99 \%$ identity to an uncultured bacterium found in a hydrogen-producing extreme thermophilic anaerobic microflora enriched from cow manure and xylose (Yokoyama et al., 2007).

In $R_{\mathrm{EHTG}}$ system, clone inserts closely related to genera Clostridium, Sporolactobacillus, Bacillus, Klebsiella and Thermoanaerobacterium were obtained (Table 3). Clones exhibiting high sequence identity to Clostridium beijerinckii (99\% identity), Clostridium corinoforum (99\%) and Klebsiella sp. (99\%) (Fig. 5 and Table
SI

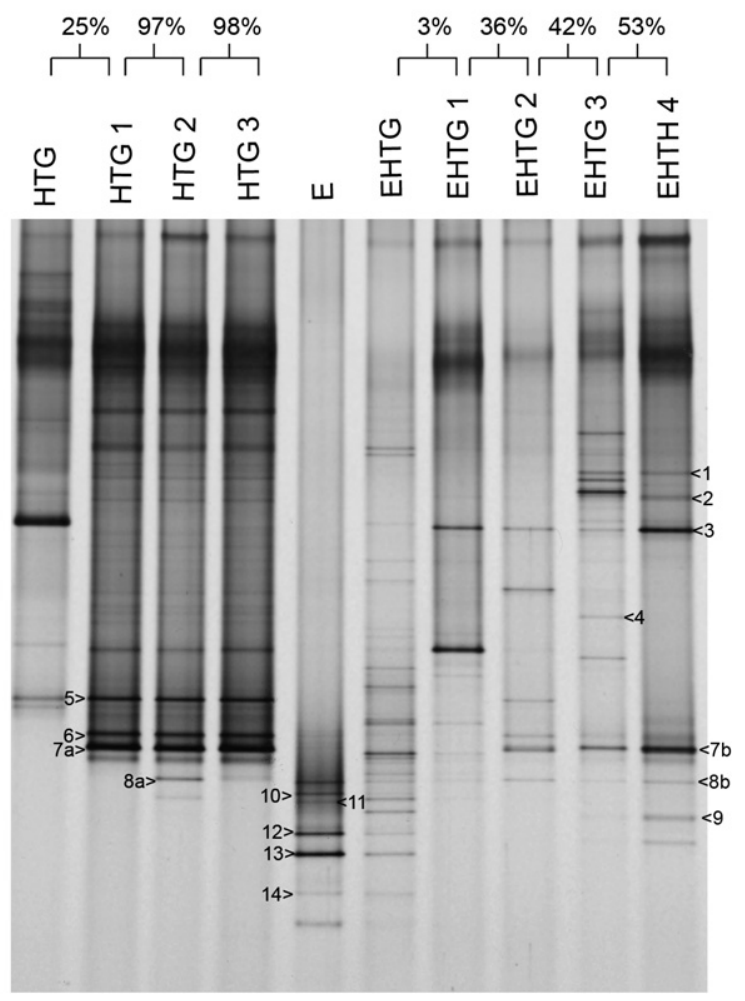

Fig. 5. DGGE profile of granules before $(G)$ and after heat treatment (HTG), the enriched culture (E) and granules after the contact with the enriched culture (EHTG); heat treated granules system on day 23 (HTG 1), day 34 (HTG 2) and day 44 (HTG 3); engineered heat treated granules system on day 4 (EHTG 1), day 7 (EHTG 2), day 15 (EHTG 3) and day 38 (EHTG 4). Similarity index (SI).

Table 2

Samples collected from $R_{\mathrm{EHTG}}$ and $R_{\mathrm{HTG}}$, condition prevailing at the time of sampling.

\begin{tabular}{llll}
\hline Sample & Operational period & $\begin{array}{l}\text { Feed concentration } \\
\left(\mathrm{g} \mathrm{COD}^{-1}\right)\end{array}$ & $\begin{array}{l}\text { Hydraulic retention } \\
\text { time }(h)\end{array}$ \\
\hline$R_{\mathrm{HTG}} 1$ & $R_{\mathrm{EHTG}}$ day 23 & 5 & 13 \\
$R_{\mathrm{HTG}} 2$ & $R_{\mathrm{EHTG}}$ day 34 & 5 & 8 \\
$R_{\mathrm{HTG}} 3$ & $R_{\mathrm{EHTG}}$ day 44 & 5 & 8 \\
$R_{\mathrm{EHTG}} 1$ & $R_{\mathrm{EHTG}}$ day 4 & 2 & 27 \\
$R_{\mathrm{EHTG}} 2$ & $R_{\mathrm{EHTG}}$ day 7 & 5 & 27 \\
$R_{\mathrm{EHTG}} 3$ & $R_{\mathrm{EHTG}}$ day 15 & 5 & 14 \\
$R_{\mathrm{EHTG}} 4$ & $R_{\mathrm{EHTG}}$ day 38 & 5 & 8 \\
\hline
\end{tabular}

3) corresponded to bands resolving in the upper positions of DGGE profiles from $R_{\mathrm{EHTG}}$ (bands 1, 2 and 3) but were apparently absent in $R_{\mathrm{HTG}}$. The presence of those potential hydrogen producing bacteria clustering within the Clostridium and Klebsiella genus, was the main difference found when comparing the DGGE profiles (number and intensity of bands) of both systems. Previous studies have also reported the potential of using Clostridium and Klebsiella to produce hydrogen from a variety of carbohydrates (Sen Gupta et al., 2005).

Bacillus-like organisms were also found in $R_{\mathrm{EHTG}}$ DGGE profiles, and during the transient peaks of hydrogen production in $R_{\mathrm{HTG}}$ (band $8 \mathrm{a}$ and $8 \mathrm{~b}$ in lanes HTG2 and EHTG4 in Table 4, Fig. 5). Microorganisms affiliated with the Thermoanaerobacterium genus, were present in both, $R_{\mathrm{HTG}}$ and $R_{\mathrm{EHTG}}$ DGGE profiles (Table 3 and 4). However, in $R_{\text {EHTG }}$ the band corresponding to a closest relative of Thermoanaerobacterium thermosacharolyticum (band 7b) became stronger only at the end of operation time. T. thermosacharolyticum 
Table 3

Phylogenetic affiliations of cloned 16S rRNA gene sequences corresponding to identified bands in the DGGE profiles.

\begin{tabular}{|c|c|c|c|c|c|}
\hline $\mathrm{BM}^{\mathrm{a}}$ & Phylum $^{\mathrm{b}}$ & Class $^{\mathrm{b}}$ & Affiliation $^{c}$ & $\mathrm{Acc}^{\mathrm{d}}$ & Identity (\%) \\
\hline 1 & Firmicutes & Clostridia & Clostridium corinoforum (X76742.1) & GU296463 & 99 \\
\hline 2 & Firmicutse & Clostridia & Clostridium beijerinckii (EF446166.1) & GU296464 & 99 \\
\hline 3 & Proteobacteria & Gammaproteobacteria & Klebsiella sp. (DQ358738.1) & GU296465 & 99 \\
\hline 4 & Firmicutes & Bacilli & Sporolactobacillus inulinos (AB362770.1) & GU296466 & 96 \\
\hline 5 & Firmicutes & Clostridia & Thermoanaerobacterium thermosacharolyticum (EF680277.1) & GU296467 & 97 \\
\hline 6 & Firmicutes & Clostridia & Thermoanaerobacterium thermosacharolyticum (EU563362.1) & GU296468 & 99 \\
\hline $7 a$ & Firmicutes & Clostridia & Thermoanaerobacterium thermosacharolyticum (EF680277.1) & GU296469 & 99 \\
\hline $7 \mathrm{~b}$ & Firmicutes & Clostridia & Thermoanaerobacterium thermosacharolyticum (EF680277.1) & GU296470 & 100 \\
\hline $8 a$ & Firmicutes & Bacilli & Bacillus coagulans (DQ297928.1) & GU296471 & 99 \\
\hline $8 \mathrm{~b}$ & Firmicutes & Bacilli & Bacillus coagulans (AB116136.1) & GU296472 & 99 \\
\hline 9 & Firmicutes & Bacilli & Sporolactobacillus nakayamae (АВ362637.1) & GU296473 & 95 \\
\hline 10 & Firmicutes & Clostridia & Uncultured bacterium (AB286973.1) & GU296474 & 99 \\
\hline 11 & Firmicutes & Clostridia & Caldicoprobacter oshimai (AB450762.1) & GU296475 & 99 \\
\hline 12 & Firmicutes & Clostridia & Thermoanaerobacter subterraneus (AY216597.1) & GU296476 & 99 \\
\hline 13 & Firmicutes & Clostridia & Thermoanaerobacter subterraneus (AY216597.1) & GU296477 & 99 \\
\hline 14 & Firmicutes & Clostridia & Thermoanaerobacter tengcongensis (AE008691.1) & GU296478 & 99 \\
\hline
\end{tabular}

a Band mark in Fig. 5.

b Classified using the RDP Naive Bayesian Classifier (Wang et al., 2007).

c Closest organisms in GenBank with accession number.

d GenBank accession number.

Table 4

Samples collected from $R_{\mathrm{EHTG}}$ and $R_{\mathrm{HTG}}$, reactors performance and dominant bacteria ribotypes present.

\begin{tabular}{|c|c|c|}
\hline Sample & $\begin{array}{l}\text { Process performance ( } \mathrm{ml} \\
\left.\mathrm{H}_{2} \mathrm{l}^{-1} \text { day }^{-1}\right)\end{array}$ & Closest organisms in GenBank \\
\hline$R_{\mathrm{HTG}} 1$ & 2 & Thermoanaerobacterium thermosacharolyticum \\
\hline$R_{\mathrm{HTG}} 2$ & 1047 & Thermoanaerobacterium thermosacharolyticum; Bacillus coagulans \\
\hline$R_{\mathrm{HTG}} 3$ & 56 & Thermoanaerobacterium thermosacharolyticum \\
\hline$R_{\mathrm{EHTG}} 1$ & 147 & Klebsiella sp. \\
\hline$R_{\mathrm{EHTG}} 2$ & 975 & Klebsiella sp.; Thermoanaerobacterium thermosacharolyticum; Bacillus coagulans \\
\hline$R_{\mathrm{EHTG}} 3$ & 1380 & $\begin{array}{l}\text { Clostridium corinoform; Klebsiella sp.; Sporolactobacillus inulinus; Thermoanaerobacterium thermosacharolyticum; Bacillus } \\
\text { coagulans }\end{array}$ \\
\hline$R_{\mathrm{EHTG}} 4$ & 2597 & $\begin{array}{l}\text { Clostridium corinoform; Clostridium beijerinckii; Klebsiella sp.; Thermoanaerobacterium thermosacharolyticum; Bacillus } \\
\text { coagulans; Sporolactobacillus sp. }\end{array}$ \\
\hline
\end{tabular}

is known by the capability of producing hydrogen as well as lactate and volatile fatty acids from a variety of sugars, including glucose and arabinose (Altaras et al., 2001). T. thermosacharolyticum was also immobilized on heat treated methanogenic granules by O-Tong and co-authors for high-rate continuous hydrogen production (Thong et al., 2008).

The presence of an enriched and active hydrogen producing culture during the start-up of $R_{\text {EHTG }}$ system might be crucial for the efficient hydrogen production afterwards, since lactic acid was not produced in high concentration in $R_{\mathrm{EHTG}}$ during the first periods of operation as it was in $R_{\mathrm{HTG}}$ system. Organisms from class Clostridia (closest related to Thermoanaerobacter subteraneus, Thermoanaerobacter tengcongensis and Caldicoprobacter oshimai) and uncultured bacteria (lane E, Fig. 5) were present initially in the enriched hydrogen producing culture but not $T$. thermosacharolyticum. After the batch period, the $R_{\mathrm{EHTG}}$ was fed continuously. After 4 and 7 days of continuous operation, a low microbial diversity was observed and bands corresponding to organisms present in the enriched culture were not detected (Fig. 5, lanes EHTG1, EHTG2, respectively). In this period, hydrogen yield was maximal in this reactor (Table 1 ). Also the profile of microbial fermentation products (SFP) revealed that acetate was the main compound detected in the $R_{\text {EHTG }}$ effluent. Following these initial days, the hydrogen production in this reactor was stable, although the hydrogen yields tended to decrease slightly. This finding was associated with a change in the profile of soluble fermentation products where lactate increased, especially after day 38 , likely due to the decrease in the hydraulic retention time. The interesting point is that this operational behavior of $R_{\mathrm{EHTG}}$ was associated to the increasing intensity of a band affiliated with $T$. thermosacharolyticum (100\% 16S rRNA gene sequence identity). Increasing lactate production by $T$. thermosacharolyticum was reported before by Vancanneyt et al. (1990) at increasing dilution rates, which may explain the partial shift from hydrogen to lactate, observed in the experiment at the lower hydraulic retention times. Notwithstanding, the hydrogen production was still significant in later operational periods, likely due to the presence of organisms closely related to class Clostridia (Clostridium beijerinckii, Clostridium corinoforum) and class Gammaproteobacteria (Klebsiella sp.) (Table 4, Fig. 2).

The global history of $R_{\mathrm{HTG}}$ clearly indicates that hydrogen was only occasionally produced when lactate was minimal and that T. thermosacharolyticum-related bacteria were dominant in the operational time, although a band corresponding to a closest relative to Bacillus coagulans was detected in day 34.

It is therefore clear that the contact of the heat treated granules with the enriched culture favoured the continuous hydrogen production. However, immobilization of specific microorganisms of the enriched culture, such as T. subterraneus, T. tengcongensis and C. oshimai, apparently did not occur, suggesting that the microbial advantage of the EHTG reactor by comparison with the HTG was not direct and therefore the explanation is not straightforward. Some hypotheses can be pointed out:

(1) In the $R_{\mathrm{EHTG}}$, the presence, since the beginning, of an active hydrogen producing community promoted a different SFP profile, more favorable to hydrogen production. That likely resulted from the competition between the culture and the glucose and arabinose consumers present in the heat treated granules, which were still 
under activation. Interestingly, dominant organisms in the enriched culture, T. subterraneus (99\% 16S rRNA gene sequence similarity) and T. tengcongensis (99\%), might not consume arabinose (Fardeau et al., 2000; Xue et al., 2001). Therefore, arabinose was likely available for other organisms eventually present in the culture but not dominant in the beginning. In particular, Klebsiella sp. is referred as a promising organism capable of utilizing pentose as carbon source to produce hydrogen (Rosenberg, 1980). From Fig. 5, band 3, the presence of Klebsiella-like organisms is evident during reactor operation. The different SFP profile could have selected for a microbial community able to produce hydrogen in this reactor.

(2) Another possible explanation for the different behavior observed in the two reactors can be the antibiotic influence of some clostridial species (ribotypes corresponding to bands 10-14, lane E, Fig. 5) present in the enriched culture, which could have favored, in $R_{\mathrm{EHTG}}$, the selection of hydrogen producing organisms in detriment of lactate producing ones. Although antibiotic production from thermophilic Clostridia has not been reported so far, antibiotic potential of other thermophiles such as bacilli and actinomycetes including was already described (Edwards, 1993; Esikova et al., 2002).

\section{Conclusions}

Significant improvement of hydrogen production and process stability was obtained in engineered heat treated granular system compared with heat treated granular system. The presence of potential hydrogen producing bacteria clustering within the Clostridium and Klebsiella genera was the main difference found between both systems, which is likely to be related to the better performance exhibited by the $R_{\mathrm{EHTG}}$ system. The contact of HTG with an enriched active hydrogen producing culture during the reactor start-up contributed to the development of a stable and efficient hydrogen production during the $R_{\mathrm{EHTG}}$ system operation.

\section{Acknowledgements}

The financial support from Fundação para a Ciência e Tecnologia (FCT) and European Community fund FEDER (Program COMPETE) through Project FCOMP-01-0124-FEDER-007087 (PTDC/BIO/69745/2006), and through the FCT PhD grants SFRH/ $\mathrm{BD} / 29823 / 2006$ given to Abreu AA and SFRH/BD/48965/2008 given to Alves JI is gratefully acknowledged. This study also received support from Danish Agency for Science, Technology and Innovation under Bio REF. Project No. 2104-06-0004.

\section{Appendix A. Supplementary data}

Supplementary data associated with this article can be found, in the online version, at doi:10.1016/j.biortech.2010.07.070.

\section{References}

Altaras, N.E., Etzel, M.R., Cameron, D.C., 2001. Conversion of sugars to 1,2propanediol by Thermoanaerobacterium thermosaccharolyticum HG-8. Biotechnol. Prog. 17, 52-56.

Angelidaki, I., Torang, L., Waul, C.M., Schmidt, J.E., 2004. Anaerobic bioprocessing of sewage sludge, focusing on degradation of linear alkylbenzene sulfonates (LAS). Water Sci. Technol. 49, 115-122.

APHA, AWWA WPC, 1989. In: Standard methods for the examination of water and wastewater, 17th ed. American Public Health Association Washington, DC, USA. Ref Type: Generic.

Chen, C.C., Lin, C.Y., Chang, J.S., 2001. Kinetics of hydrogen production with continuous anaerobic cultures utilizing sucrose as the limiting substrate. Appl. Microbiol. Biotechnol. 57, 56-64.

Das, D., Veziroglu, T.N., 2001. Hydrogen production by biological processes: a survey of literature. Int. J. Hydrogen Energy 26, 13-28.

Edwards, C., 1993. Isolation properties and potential applications of thermophilic actinomycetes. Appl. Biochem. Biotechnol. 42, 161-179.
Esikova, T.Z., Temirov, Y.V., Sokolov, S.L., Alakhov, Y.B., 2002. Secondary antimicrobial metabolites produced by thermophilic Bacillus sp. strains VK2 and VK21. Appl. Biochem. Microbiol. 38, 226-231.

Fardeau, M.L., Magot, M., Patel, B.K.C., Thomas, P., Garcia, J.L., Ollivier, B., 2000. Thermoanaerobacter subterraneus sp. nov., a novel thermophile isolated from oilfield water. Int. J. Syst. Evol. Microbiol. 50, 2141-2149.

Hames, B.D., Hooper, N.M., 2000. Instant notes in biochemistry. In: Instant Notes in Biochemistry, second ed. BIOS Scientific Publishers Limited, United Kingdom, pp. 278-301. Ref Type: Generic.

Hane, B.G., Jager, K., Drexler, H.G., 1993. The Pearson product-moment correlationcoefficient is better suited for identification of DNA fingerprint profiles than band matching algorithms. Electrophoresis 14, 967-972.

Hawkes, F.R., Hussy, I., Kyazze, G., Dinsdale, R., Hawkes, D.L., 2007. Continuous dark fermentative hydrogen production by mesophilic microflora: principles and progress. Int. J. Hydrogen Energy 32, 172-184.

Kadar, Z., De Vrijek, T., van Noorden, G.E., Budde, M.A.W., Szengyel, Z., Reczey, K., Claassen, P.A.M., 2004. Yields from glucose, xylose, and paper sludge hydrolysate during hydrogen production by the extreme thermophile Caldicellulosiruptor saccharolyticus. Appl. Biochem. Biotechnol. 113, 497-508.

Kim, J.O., Kim, Y.H., Ryu, J.Y., Song, B.K., Kim, I.H., Yeom, S.H., 2005. Immobilization methods for continuous hydrogen gas production biofilm formation versus granulation. Process Biochem. 40, 1331-1337.

Kotsopoulos, T.A., Zeng, R.J., Angelidaki, I., 2006. Biohydrogen production in granular up-flow anaerobic sludge blanket (UASB) reactors with mixed cultures under hyper-thermophilic temperature $\left(70^{\circ} \mathrm{C}\right)$. Biotechnol. Bioeng. 94, 296-302.

Lay, J.J., Lee, Y.J., Noike, T., 1999. Feasibility of biological hydrogen production from organic fraction of municipal solid waste. Water Res. 33, 2579-2586.

Lee, K.S., Lo, Y.S., Lo, Y.C., Lin, P.J., Chang, J.S., 2003. H-2 production with anaerobic sludge using activated-carbon supported packed-bed bioreactors. Biotechnol. Lett. 25, 133-138.

Lee, K.S., Wu, J.F., Lo, Y.S., Lo, Y.C., Lin, P.J., Chang, J.S., 2004. Anaerobic hydrogen production with an efficient carrier-induced granular sludge bed bioreactor. Biotechnol. Bioeng. 87, 648-657.

Levin, D.B., Pitt, L., Love, M., 2004. Biohydrogen production: prospects and limitations to practical application. Int. J. Hydrogen Energy 29, 173-185.

Lin, C.Y., Cheng, C.H., 2006. Fermentative hydrogen production from xylose using anaerobic mixed microflora. Int. J. Hydrogen Energy 31, 832-840.

Liu, D.W., Liu, D.P., Zeng, R.J., Angelidaki, I., 2006. Hydrogen and methane production from household solid waste in the two-stage fermentation process. Water Res. 40, 2230-2236.

Liu, D.W., Zeng, R.J., Angelidaki, I., 2008. Effects of $\mathrm{pH}$ and hydraulic retention time on hydrogen production versus methanogenesis during anaerobic fermentation of organic household solid waste under extreme thermophilic temperature $\left(70{ }^{\circ} \mathrm{C}\right)$. Biotechnol. Bioeng. 100, 1108-1114.

Lu, J.Q., Gavala, H.N., Skiadas, I.V., Mladenovska, Z., Ahring, B.K., 2008. Improving anaerobic sewage sludge digestion by implementation of a hyper-thermophilic prehydrolysis step. J. Environ. Manage. 88, 881-889.

$\mathrm{Mu}$, Y., Yu, H.Q., 2006. Biological hydrogen production in a UASB reactor with granules. I. Physicochemical characteristics of hydrogen-producing granules. Biotechnol. Bioeng. 94, 980-987.

Noike, T., Mizuno, O., 2000. Hydrogen fermentation of organic municipal wastes. Water Sci. Technol. 42, 155-162.

Noike, T., Takabatake, H., Mizuno, O., Ohba, M., 2002. Inhibition of hydrogen fermentation of organic wastes by lactic acid bacteria. Int. J. Hydrogen Energy 27, 1367-1371.

Oh, S.E., Lyer, P., Bruns, M.A., Logan, B.E., 2004. Biological hydrogen production using a membrane bioreactor. Biotechnol. Bioeng. 87, 119-127.

Rosenberg, S.L., 1980. Fermentation of pentose sugars to ethanol and other neutral products by microorganisms. Enzyme Microbial Technol. 2, 185-193.

Sanguinetti, C.J., Neto, E.D., Simpson, A.J.G., 1994. Rapid silver staining and recovery of PCR products separated on polyacrylamide gels. Biotechniques 17 , 914.

Sen Gupta, B., Hashim, M.A., Ramachandran, K.B., Sen Gupta, L., Cui, Z.E., 2005. The effect of gas sparging in cross-flow microfiltration of 2,3-butanediol fermentation broth. Eng. Life Sci. 5, 54-57.

Strobel, H.J., 1993. Evidence for catabolite inhibition in regulation of pentose utilization and transport in the ruminal bacterium Selenomonas ruminantium. Appl. Environ. Microbiol. 59, 40-46.

Tay, J.H., Liu, Q.S., Liu, Y., 2001. Microscopic observation of aerobic granulation in sequential aerobic sludge blanket reactor. J. Appl. Microbiol. 91, 168-175.

Thong, S., Prasertsan, P., Karakashev, D., Angelidaki, I., 2008. High-rate continuous hydrogen production by Thermoanaerobacterium thermosaccharolyticum PSU-2 immobilized on heat-pretreated methanogenic granules. Int. J. Hydrogen Energy 33, 6498-6508.

van Groenestijn, J.W., Geelhoed, J.S., Goorissen, H.P., Meesters, K.P.M., Stams, A.J.M., Claassen, P.A.M., 2009. Performance and population analysis of a non-sterile trickle bed reactor inoculated with Caldicellulosiruptor saccharolyticus, a thermophilic hydrogen producer. Biotechnol. Bioeng. 102, 1361-1367.

van Groenestijn, J.W., Hazewinkel, J.H.O., Nienoord, M., Bussmann, P.J.T., 2002. Energy aspects of biological hydrogen production in high rate bioreactors operated in the thermophilic temperature range. Int. J. Hydrogen Energy 27, 1141-1147.

Vancanneyt, M., Devos, P., Vennens, L., Deley, J., 1990. lactate and ethanol dehydrogenase-activities in continuous cultures of Clostridium thermosaccharolyticum Lmg-6564. J. Gen. Microbiol. 136, 1945-1951. 
Wang, Q., Garrity, G.M., Tiedje, J.M., Cole, J.R., 2007. Naive Bayesian classifier for rapid assignment of rRNA sequences into the new bacterial taxonomy. Appl. Environ. Microbiol. 73, 5261-5267.

Wu, S.Y., Hung, C.H., Lin, C.N., Chen, H.W., Lee, A.S., Chang, J.S., 2006. Fermentative hydrogen production and bacterial community structure in high-rate anaerobic bioreactors containing silicone-immobilized and self-flocculated sludge. Biotechnol. Bioeng. 93, 934-946.

Xue, Y.F., Xu, Y., Liu, Y., Ma, Y.H., Zhou, P.J., 2001. Thermoanaerobacter tengcongensis sp. nov., a novel anaerobic, saccharolytic, thermophilic bacterium isolated from a hot spring in Tengcong, China. Int. J. Syst. Evol. Microbiol. 51, 1335-1341.
Yokoyama, H., Moriya, N., Ohmori, H., Waki, M., Ogino, A., Tanaka, Y., 2007. Community analysis of hydrogen-producing extreme thermophilic anaerobic microflora enriched from cow manure with five substrates. Appl. Microbiol. Biotechnol. 77, 213-222.

Yu, Z.T., Morrison, M., 2004. Comparisons of different hypervariable regions of rrs genes for use in fingerprinting of microbial communities by PCR-denaturing gradient gel electrophoresis. Appl Environ Microbiol. 70, 4800-4806.

Zhang, Z.P., Show, K.Y., Tay, J.H., Liang, D.T., Lee, D.J., Su, A., 2008. The role of acid incubation in rapid immobilization of hydrogen-producing culture in anaerobic upflow column reactors. Int. J. Hydrogen Energy 33, 5151-5160. 